\title{
The Potency of Three-Chambered Microbial Desalination Cells Implementation as an Alternative Solution for Energy Conservation in Indonesia
}

\author{
Ega Adi Surya ${ }^{\mathrm{a}}$, Fachryan Zuhri ${ }^{\mathrm{a} *}$, Ratri Kirana Prabaningtyas ${ }^{\mathrm{b}}$ \\ ${ }^{a}$ Chemical Engineering Department, Bioprocess Engineering Course, Faculty of Engineering, Universitas Indonesia \\ ${ }^{b}$ Chemical Engineering Department, Chemical Engineering Course, Faculty of Engineering, Universitas Indonesia
}

\begin{abstract}
Energy crisis issue is appearing. The fact that there will no longer be enough unrenewable energy sources to fulfill global energy demand forces us to come up with some initiatives to overcome this. One way to do it is by trying to conserve energy in any way possible, such as in the production of reliable water sources. Microbial desalination cells (MDC) is one of the methods used in salt water desalination process. It runs on bioelectric potential produced because of the metabolism done by microbes. The results of more recent findings shows that wastewater-based three-chambered MDC offers a new solution to resolve both issues concering energy and water crisis, also with higher efficiency than other common desalination process such as reverse osmosis, electrodialysis, thermal distillation, and freezing. Indonesia's nature as an archipelago country that is surrounded by enormous amount of salt water held the potential of MDC implementation to become a solution of energy crisis caused by the upcoming extinction of fossil fuel.
\end{abstract}

Keywords: Energy conservation; microbial desalination cells; seawater

Corresponding author Tel: +62 89622011819

E-mail address : fachryan.zuhrii@gmail.com

\section{Introduction}

Energy crisis appears to be a major problem for country across the world, include Indonesia. Knowing that the supply of energy mainly comes from fossil fuel, the depletion in number of fossil fuel reserves made a great impact in society. Contrary to popular belief, one of the most feasible actions that could be taken to overcome issues regarding energy crisis is to conserve it. Energy conservation can be done by reducing the amount of energy used to produce water for household consumption. Scarcity of reliable water sources in Indonesia is one of the most problematical issues that need to be solved immediately. Various solutions have been established, one of them is desalination of seawater. In this paper, we propose the potency of three-chambered microbial desalination cells (MDC) implementation in Indonesia solely because it offers a new method in seawater desalination process with lower to zero net supply of activation energy than any other current method.

\section{Methods}

In the process of writing this paper, we used literature analysis approach by reviewing journals about: 


\subsection{Energy crisis}

Energy crisis is a condition where the shortfall of the energy supply occurs. This caused by the imbalance between the rate of energy production and the growth of energy demand in society.

\subsection{Energy conservation}

Energy conservation refers to the reduction of energy consumption by using alternative technology which requires less energy service. Energy conservation is one method to safe energy. Energy conservation is not the same as energy efficiency. Energy conservation only refers to use less energy but energy efficiency means using lower energy to achieve normal result.

\subsection{Current desalination technology}

Desalination of seawater to fresh water is becoming more popular right now. Desalination is a process of removing salt from saline water using various method. The most common methods of desalination are reverse osmosis (RO), electrodialysis (ED), thermal distillation, freezing, etc [1]. All of these method consume relatively high energy due to the power required for aeration, sludge treatment, high pressure membrane process, and thermal distillation [2]. $\mathrm{RO}$ and thermal distillation require (2 to 15) $\mathrm{KWh}$ to produce $1 \mathrm{~m}^{3}$ fresh water from sea water [6].

Reverse osmosis (RO) is one of the most used method in the world. The RO process used high pressure to force water molecules through a semi-permeable membrane that retains the salts, producing fresh water and brine. This method also used chemicals in various stages of desalination process such as coagulants in the pretreatment stage (iron or aluminum salts, polymers), biocides (such as chlorine) and neutralizers (sodium sulfite), antiscalants to prevent fouling of the membranes (polyphosphates, polyphosphonates, polyacrylic acid, polymaleic acid), cleaning solutions for RO membranes (acidic and alkaline solutions and detergents), and $\mathrm{pH}$ and hardness adjustors for the product water (lime) [3]. These chemicals usually disposed along with brine.

Electrodialysis (ED) is another method to desalinate water. ED use electrical potential difference to separate ions based on its charges. Electrical charge caused cathions from sea water to move toward negative charged cathode through cathion exchanged membrane (CEM). This membrane prevent cathions to go back to the sea water. The positive charged anode will attract anions from sea water through the anion exchanged membrane (AEM). This ions movement will desalinate sea water. As said before, ED used electrical charge to desalinate water, which need a lot of energy.

\subsection{Microbial desalination cells}

Microbial desalination cells (MDC) is a new method of desalination that uses bioelectric potential produced from microbial metabolism of organic material to accomplish desalination. MDC is derived from microbial fuel cells (MFCs), a bioelectrochemical devices that convert organic materials into electrical energy [4]. This paper will discuss about a three chambered MDC, modified from MFCs by inserting an anion exchange membrane (AEM) next to the anode and cation exchange membrane (CEM) next to cathode, and the middle chamber between membrane filled with saline water [5].

MDC consists of three compartments; the anode, a compartment containing salt located in between, and the cathode. Desalinating process is happened in central compartment. The microorganism in the anode will oxidize biodegradable substrates and produced current and protons. The anions in the saline water will migrate to the anode across AEM and the protons will go through CEM to the cathode for charge balance. The loss of ionic species in the middle chamber result in desalination of sea water [6]. 


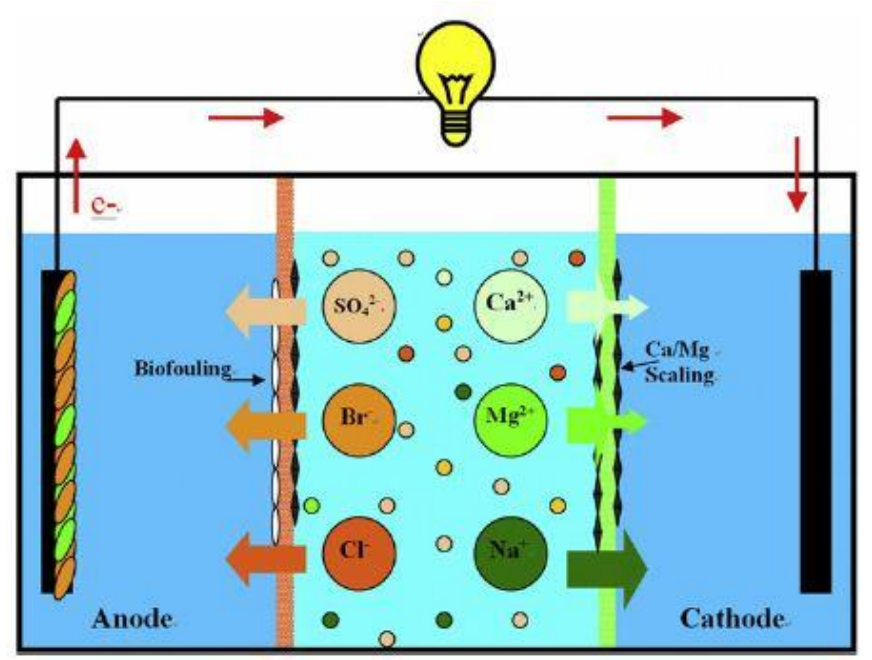

Fig. 1. MDC mechanism.

\section{Results and discussion}

\subsection{MDC performance}

Microbial desalination cells (MDC) is a new method of desalination that uses bioelectric potential produced from organic matters via microbial metabolism to accomplish desalination [2]. The efficiency of MDC can be enhance by using stacks of ion exchange membrane between the electrode and by flowing saline water through several MDC. This can resulted in $\mathrm{pH}$ imbalances between cathode and anode. One solution to overcome this problem is recirculation of the organic medium. To increase the efficiency of MDC even more, the organic medium can be flowed through several anode to cathode chamber that hydraulically connected [7]. MDC can also be used as a wastewater treatment by flowing wastewater into the anode chamber. One MDC construction can removed $38 \%$ of ammonia from the wastewater and MDC showed $52 \%$ higher COD removal than MFCs. This method can also removed $66 \%$ of salt from the desalination chamber [2].

The evolution of MDC construction is progressing within time. More researches and studies have been constructed in order to improve the efficiency of the salt removal process. This leads to the findings of threechambered system, one of MDC construction that is able to remove water salinity to up to $90 \%$ [4] with lower to zero net supply of activation energy, undoubtedly more efficient than common desalination method which consumes up to $4 \mathrm{kWh} / \mathrm{m}^{3}[3]$ in comparison.

Studies also showed that MDC can uses wastewater as its electrolyte. This goes under the principle of sustainable energy because it provides new functions for excess materials that supposedly regarded as waste. All of the supporting data makes us believe that not only will MDC emerge as a system that is able to desalinate salt water but it can also be used as a medium of wastewater treatment. In fact, the COD removal rate by MDC yield the percentage ranging from (53.8 to 92) \% [4]. In conclusion, MDC is great system not only because it consumes less to no energy, but it also generates electricity by itself that, and make this become low cost system and gives significant environmental benefit [5]. 


\subsection{The potency of MDC implementation in Indonesia}

\subsubsection{Geographical potential}

In this paper, we evaluate the potency of MDC implementation based on few different aspects. First, from the geographical point of view, we know that Indonesia, as a country that consists of many islands, is naturally surrounded by high amount of ocean and sea region. Indonesian Republic often crowned as the biggest archipelagic state in the world considering the 17499 islands, 5,8 million $\mathrm{km}^{2}$ sea-region area, and a coast line that spread across the country for about $8000 \mathrm{~km}$ [1]. The 5,8 milllion $\mathrm{km}^{2}$ or approximately $2 / 3$ of the total Indonesian area consists of 2,7 million $\mathrm{km}^{2}$ area of ZEE (Zona Ekonomi Ekslusif) and 3,1 million $\mathrm{km}^{2}$ area of territorial sea. From a different source, it is also said that by agreement that has been appointed by UNCLOS in 1982 about 'International Sea Law' (that has been officially ratified in 19 November 1993, signed by 60 UN-member countries, and officially legitimated in 16 November 19194) Indonesia still has the rights to claim LKRI (Landas Kontinen Republik Indonesia) as far as 350 miles measured from the tip of the territorial line. With this convention, it means that the sea-region that could be utilized by Indonesia is increased to the amount of approximately 6,7 million $\mathrm{km}^{2}$ that consists of 3,1 million $\mathrm{km}^{2}$ sea-region area and 3,6 million $\mathrm{km} 2$ area of ZEE and LKRI (Bakosurtanal, 1997). Those region could potentially be utilized as the main source of sea water for the MDC system.

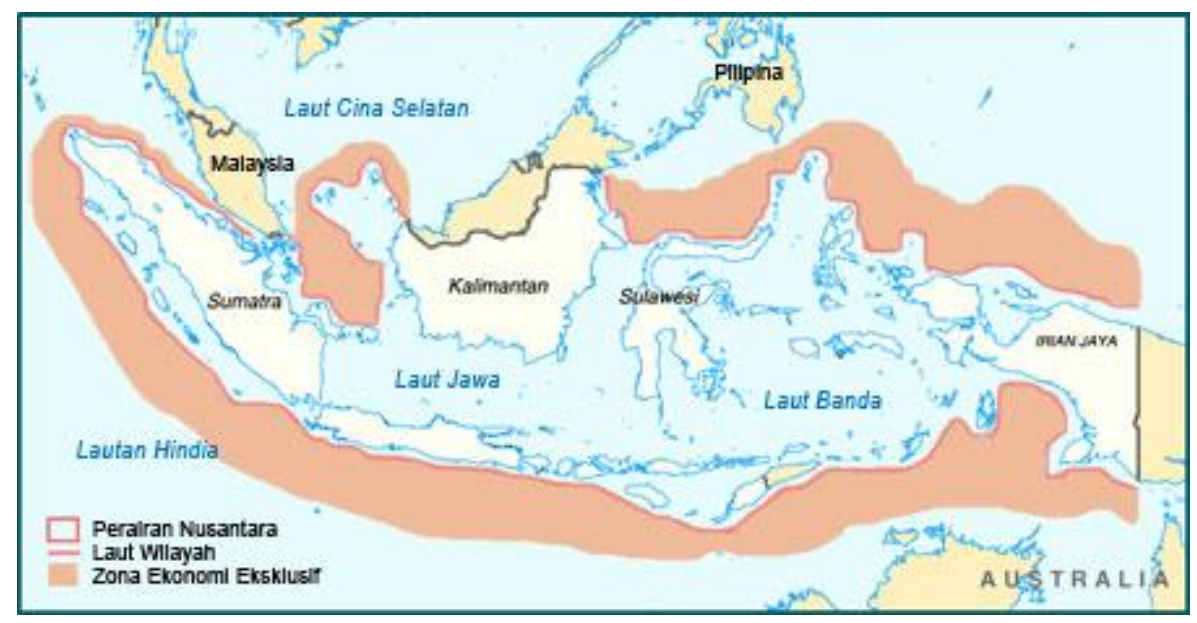

Fig. 2. Map of Indonesia's sea region.

\subsubsection{Various microorganisms in Indonesia}

Based in the optimum temperature for the growth of microorganism, in general, microorganism is divided into four classes : psycrophilic bacteria that lives in the range of (0 to 20) ${ }^{\circ} \mathrm{C}$, psychotropic that lives in (0 to 35) ${ }^{\circ} \mathrm{C}$, mesophilic that lives in $(20 \text { to } 45)^{\circ} \mathrm{C}$, thermophilic in $(45$ to 65$){ }^{\circ} \mathrm{C}$, and hyperthermophilic that lives to up to $90{ }^{\circ} \mathrm{C}$ (Prescott, 2005 122-124). 


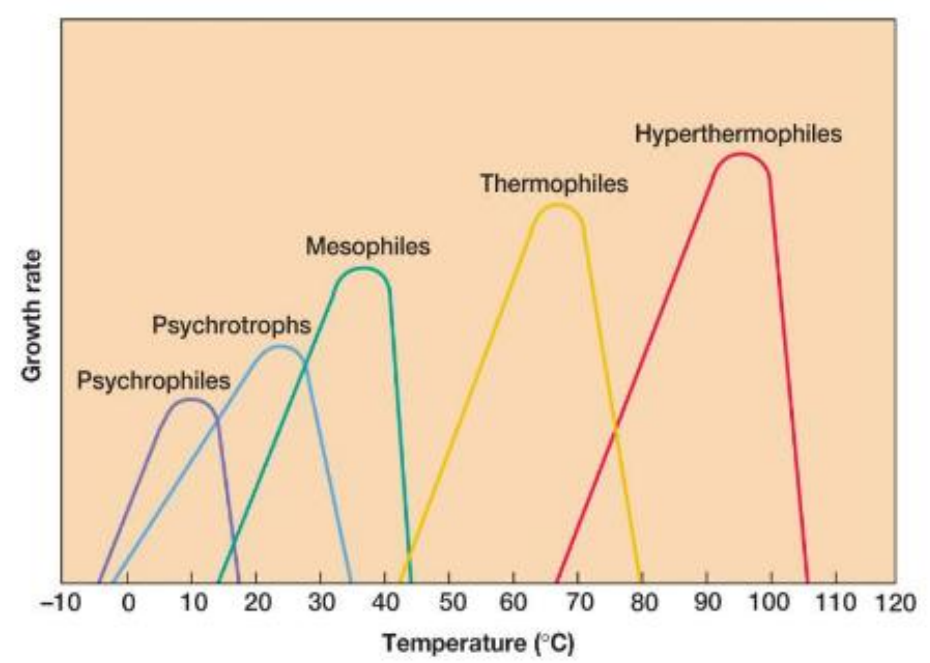

Fig. 3. Temperature for optimum growth of microorganism (Prescott, 2005:124).

Viewed from geographical perspective, the $5^{\circ} 00^{\prime} \mathrm{N}$ latitude and $120^{\circ} 00^{\prime} \mathrm{E}$ longitude of Indonesia from the Northern Hemisphere signifies its proximity to the equator. Indonesia as an equatorial-region country is characterised by the almost entirely tropical climate with the coastal plains averaging $28{ }^{\circ} \mathrm{C}$, the inland and mountain areas averaging $26{ }^{\circ} \mathrm{C}$, and the higher mountain regions, $23{ }^{\circ} \mathrm{C}$. This geographical data, if we relate it to the standard of appropriate living temperature for microbes, provides a proper living condition for mesophilic microbes. Also, as a country with almost entirely tropical climate, Indonesia has so many regions that is geothermally active, such as volcanic mountain ranges, naturally occuring hot-water springs, and oil and gas reserves. Such environment condition could induce the high occurence of thermophilic bacteria heterogenity (Indrajaya et al., 2003 : 53-56). In fact, scientists have been able to isolate thermophilic bacteria from many hotwater springs in Indonesia. For example, Karina et al., have succesfully isolate and identify Pseudomonas sp. and Vibrio sp. from Songgoriti springs and Helin et al, have isolate and identify thermopilic bacteria found in Gedong Songo springs. All of these supporting data made us realize that Indonesia provides a proper condition for microbes used in the MDC method to live, so that there is no need to import a batch of microbes from another state because we could easily find the raw materials in our own.

\subsubsection{Energy outlook}

If we compare the MDC system to other desalination method, such as reverse osmosis (RO), MDC requires significantly less amount fund to sustain the system since MDC system runs on the energy that exerted by itself so there is no need to supply external amount of energy. Figure below shows an example of cost breakdown of drinking-water production by reverse osmosis in ten year. 


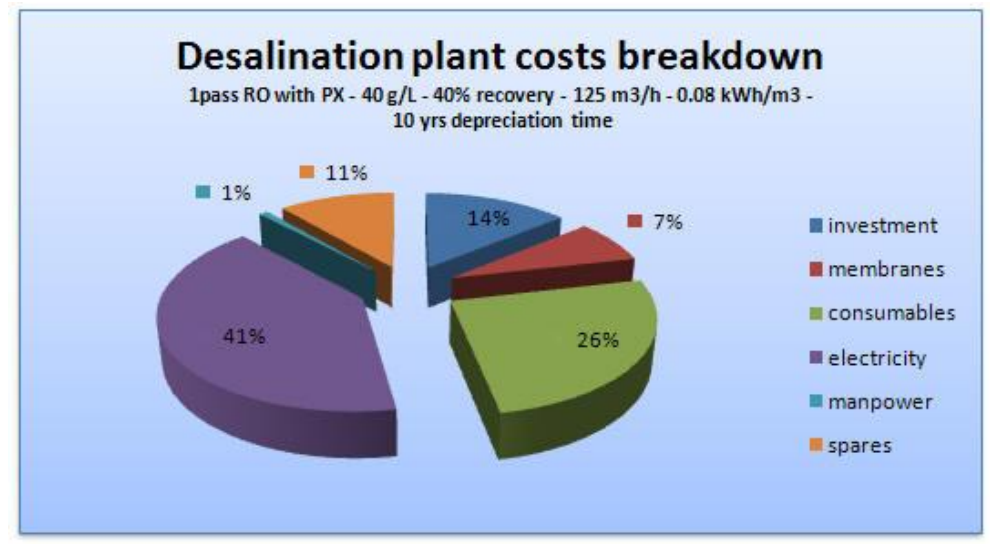

Fig. 4. Example of production cost for reverse osmosis implementation (Lenntech, 2000).

Figure above shows that the costs needed to fund the reverse osmosis plant mostly distributed to pay the electricity bill which is the main resource of energy in the reverse osmosis method. By implementing MDC system, these fund distribution could be eliminated so that the utilization cost can be reduce much lower than in the reverse osmosis system.

\section{Conclusion}

This literary analysis research render to a conclusion that Indonesia has the potential of executing the microbial desalination cells in purpose to solve issues regarding energy crisis by conserving the energies that supposedly be used to desalinate water.

\section{References}

[1] Busch, M., Mickols, W.E., "Reducing energy consumption in seawater desalination", Desalination, vol.165, pp 299-312, 2004.

[2] Kristen S. Brastad and Zhen He, "Water softening using microbial desalination cell technology", Desalination, vol. 309, pp 32-37, October 2012.

[3] M. Busch, R. Chu, U. Kolbe, Q. Meng, and SS.Li, "Ultrafiltration pretreatment to reverse osmosis for seawater desalination-three years field experience in the wangtan Datang power plant", Desalination and water treatment, vol. 10, pp1-20, 2009.

[4] Younggy Kim and Bruce E. Logan, "Microbial desalination cell for energy production and desalination", Desalination, vol xxx, pp xxx-xxx.

[5] Xiaoxinca, Xiahuang, et al, "A New Method for Water Desalination Using Microbial Desalination Cells", Environ. Sci. Technol, vol. 43, pp 7148-7142, 2009.

[6] Haiping Luoa, Pei Xub, Peter E. Jenkinsc, Zhiyong Rena, "Ionic composition and transport mechanisms in microbial desalination cells",Journal of Membrane Science, vol 209-410, pp 16-23, 2012.

[7] Youpeng Qu, Yujie Feng, Jia Liu, Weihua He, Xinxin Shi, Qiao Yang, Jiangwei, Bruce E. Logan, "Salt removal using multiple microbial desalination cells under continuous flow conditions" Desalination, vol 317, pp 17-22, 2013.

[8] Qinxue Wen, Huichao Zhang, Zhiqiang Chen, Yufei Li, Jun Nan, Yujie Feng, "Using bacterial catalyst in the cathode of microbial desalination cell to improve wastewater treatment and desalination" Bioresource Technology, vol 125, pp 108-113, 2012.

[9] HemingWang, Zhiyong Jason Ren, “A comprehensive review of microbial electrochemical systems as a platform technology" Biotechnology Advances, vol 31, pp 1798-1807, 2013.

[10] S.V. Mohan, G. Mohanakrishna, P.N. Sarma, "Effect of anodic metabolic function on bioelectricity generation and substrate degradation in single chambered microbial fuel cell”, Environ. Sci. Technol, vol. 42, pp 8088-8094, 2008. 